CORRESPONDENCE

\section{There is more to post-termination boundary violations than sex}

I enjoyed Sarkar's (2009) article and the accompanying commentary by Sheather (2009). I would simply like to add that there are situations other than sexual ones in which such boundary violations can occur. Some of these can be relatively innocent, such as a former patient doing a few odd jobs around the house. Others can be more sinister, such as the recruitment of former patients into religious groups. Sometimes it is impossible to avoid having an ongoing relationship with a former patient. Nonetheless, in all such situations it is incumbent on the doctor in question to make certain that there is nothing exploitative in that relationship.

Sarkar S (2009) Life after therapy: post-termination boundary violations in psychiatry and psychotherapy. Advances in Psychiatric Treatment; 15: 82-7.

Sheather J (2009) Trust and the therapeutic bond: the special case of psychiatry. Invited commentary on... Post-termination boundary violations. Advances in Psychiatric Treatment: 15: 88-9.

Larkin J. Feeney Consultant Psychiatrist, Cluain Mhuire Family Centre, Newtownpark Avenue, Blackrock, Co. Dublin, Ireland. Email: larkinfeeney@gmail.com

doi: 10.1192/apt.15.4.318

\section{Boundary violations and attachment}

Sarkar (2009) argues that transference is the crucial ethical obstacle to sexual relationships between psychiatrists, psychotherapists and patients, present and past. However, as he rightly points out, transference and power inequalities are ubiquitous. In the invited commentary, Sheather (2009) highlights the purpose of the doctor-patient relationship to allow the divulgence of intimate details required for treatment, and that it is the intrinsic emotional vulnerability of psychiatric patients that underpins the prohibition on relationships with them (although Sarkar has already argued that this may be patronising and stigmatising and in any case emotional vulnerability per se is no obstacle to relationships in other contexts).

Attachment theory describes how mammals are instinctually driven, via the attachment system of behaviours, to seek proximity to a caregiver or 'secure base', who provides the security that is a precondition for exploration (Ma 2006). Psychotherapeutic encounters differ from other medical encounters in the degree to which clinicians set out purposefully to cultivate an attachment relationship with patients (Ma 2007). As Bowlby
(1988) writes: the first task of psychotherapy is to 'provide the patient with a secure base from which he can explore the various unhappy and painful aspects of his life'.

It is the existence of this attachment relationship, deliberately pursued as a psychotherapeutic means and end, beyond either transference or vulnerability, which sets apart the relationship between psychiatrist or psychotherapist and patient. A romantic relationship after a psychotherapeutic relationship inevitably exploits the (psychotherapeutic) attachment relationship.

Bowlby J (1988) A Secure Base: Clinical Applications of Attachment Theory. Routledge.

Ma K (2006) Attachment theory in adult psychiatry. Part 1: Conceptualisations, measurement and clinical research findings. Advances in Psychiatric Treatment; 12: 440-9.

Ma K (2007) Attachment theory in adult psychiatry. Part 2: Importance to the therapeutic relationship. Advances in Psychiatric Treatment; 13: 10-6.

Sarkar S (2009) Life after therapy: post-termination boundary violations in psychiatry and psychotherapy. Advances in Psychiatric Treatment, 15: 82-7.

Sheather J (2009) Trust and the therapeutic bond: the special case of psychiatry. Invited commentary on... Post-termination boundary violations. Advances in Psychiatric Treatment; 15: 88-9.

Daniel McQueen Specialist Registrar in Psychotherapy, Casse Hospital, West London Mental Health Trust. Email: daniel. mcqueen@virgin.net

doi: 10.1192/apt.15.4.318a

\section{Author's reply}

I thank Drs Feeney and McQueen for their thoughtful observations. Dr Feeney is of course correct in pointing out that post-termination boundary violations, much like boundary violations during treatment, occupy a broad range. Sexual activity is at one end of spectrum and attracts most of the negative consequences, both for the patient and the therapist. It also attracts the more punitive sanctions, in civil as well as criminal courts. The 'milder' forms of boundary violation can be seemingly innocuous, for example employing an ex-patient to do small jobs. It is debatable whether such actions can cause harm to the patient, but it can be argued with relative force that the new relationship (say of employer and employee) is based on something that misuses trust, or trust obtained in the course of a fiduciary relationship. The damage caused may not be immediately obvious but is there for all to see if one is so minded. Given that the therapist can access a large pool of people for establishing such a relationship, it remains open to interpretation why a patient is recruited. Some authors (Gutheil 1993) call these ‘minor' transgressions, boundary crossing, 
rather than boundary violations. I personally do not believe that this artificial distinction actually adds anything to the discourse, a discourse based on the timeless notion of trust in the profession (Sarkar 2004). More than the actual act, it is the degree of exploitation, not as felt by the therapist necessarily but as perceived by others (including the patient), that essentially influences outcomes.

Dr McQueen very correctly brings the concept of attachment into the mix. Although schools of psychotherapy are divided on how much 'transference' is responsible for therapy, the concept of attachment is less contentious. Attachment is all pervasive, and healthy attachment is necessary not only in therapy but in general development. Research is emerging on the fact that early attachment behaviour is replicated in adult behaviour, including attachment behaviour as adults. This could be attachment to partners, children or therapists. Attachment behaviour is central to interpersonal relationships, of which the therapist-patient relationship is but one. Whether one calls it transference or attachment matters little as long as it is agreed that it is the dynamic of a therapeutic dyad that is perhaps curative or facilitatory in treatment. The scenarios I discussed in my original article (Sarkar 2004) have dysfunctional attachment (on the part of both the therapist and the patient) at their core, which may manifest as abuse of transference or merely abuse of one's position as a doctor.

Gutheil TG, Gabbard G0 (1993) The concept of boundaries in clinical practice: theoretical and risk management dimensions. American Journal of Psychiatry; 150: 188-96.

Sarkar SP (2004) Boundary violation and sexual exploitation in psychiatry and psychotherapy: a review. Advances in Psychiatric Treatment; 10: 312-20.

Sameer P. Sarkar Forensic and General Psychiatrist, PO Box 3544, Wokingham, Berkshire RG40 9FA, UK. Email: spsarkar@ onetel.com

doi: 10.1192/apt.15.4.318b

\section{Antidepressants and bleeding}

In Palaniyappan et al's (2009) useful article, the side-effects of combination treatments neatly follow the description of each combination, but none mentions bleeding. Abnormal bleeding with selective serotonin reuptake inhibitors (SSRIs) has been studied and reviewed. One of the authors (Nick Ferrier) has written on the subject and recommended caution when prescribing SSRIs to patients at risk of gastrointestinal bleeds in particular (Paton 2005).

Palaniyappan et al note that the best-evidenced combination antidepressant treatment is an SSRI plus either a noradrenergic and specific serotonergic antidepressant (NaSSA) or trazodone. Meijer et al (2004) have demonstrated that the degree of inhibition of serotonin reuptake is associated with risk of abnormal bleeding. Furthermore, de Abajo et al (1999) found that the highest association between antidepressant use and gastrointestinal bleeds occurs with trazodone (despite it being a weak serotonin reuptake inhibitor). It may be reasonable, therefore, to expect the combination of an SSRI and trazodone, through differing mechanisms, to be associated with significant abnormal bleeding.

de Abajo FJ, Rodríguez LAG, Montero D (1999) Association between selective serotonin reuptake inhibitors and upper gastrointestinal bleeding: population based case control study. BMJ; 319: 1106-9.

Meijer WEE, Heerdink ER, Nolen WA, et al (2004) Association of risk of abnormal bleeding with degree of serotonin reuptake inhibition by antidepressants. Archives of Internal Medicine; 164: 2367-70.

Palaniyappan L, Insole L, Ferrier N (2009) Combining antidepressants: a review of evidence. Advances in Psychiatric Treatment, 15: 90-9.

Paton C, Ferrier IN (2005) SSRIs and gastrointestinal bleeding. BMJ; 331: 529-30.

Andrew Al-Adwani Consultant psychiatrist, Great Oaks, Ashby High Street, Ashby, North Lincolnshire DN16 2JX, UK. Email:

al-adwani@ntlworld.com

doi: 10.1192/apt.15.4.319 